\title{
Variation in molecular stacking resulting from the different polarity of liquid crystalline molecules: synthesis and study of azo dye compounds
}

\author{
LONG-LI LAI*, ESHIN WANG \\ Department of Applied Chemistry, National Chi Nan University, Puli, \\ Taiwan 545, ROC \\ YI-HUNG LIU and YU WANG \\ Instrumentation Center and Department of Chemistry, \\ National Taiwan University, Taipei, Taiwan 106, ROC
}

(Received 28 December 2001; accepted 7 February 2002)

\begin{abstract}
To investigate the effect of molecular polarity on the packing of liquid crystalline molecules, two liquid crystals, $N, N$-disubstituted aminophenylazo-4-alkylbenzenes were synthesized and studied by single crystal structure determination. A comparison of the resulting molecular stacking with that of $N, N$-disubstituted aminophenylazo-4-butylbenzoate was made.
\end{abstract}

\section{Introduction}

Supramolecular aggregatio $\mathrm{n}$ by molecular self-assembly is an important issue in the field of structural chemistry [1]. In addition to electrostatic interaction, non-covalent forces also play a significant role in determining the structural stacking and properties of molecular assemblies [2]. The interaction between the functional molecules is found to be critical for molecular packing in crystallization [3]; furthermore the stability and phase behaviour of mesogenic molecules have been reported to arise therefrom [4]. Previously, we studied two liquid crystals, azo dyes 1 and $\mathbf{2}$, by single crystal structure determination [5]. During examination of their molecular stacking, we found that the polarity of the liquid crystals affects the molecular arrangement during crystallization. On the basis of crystallographic study, the molecular stacking of compound $\mathbf{1}$ is shown in figure 1. Molecules in the same layer are directed head-to-head and tailto-tail (for example, molecules a1-a3 in the layer A), but molecules in adjacent layers are directed by a headto-tail arrangement (for example, molecules a1-a3 in layer A and molecules b1-b3 in layer B) [5a]. Apparently, the carboxylate and amido groups in compound $\mathbf{1}$ are both strongly polar moieties. For greatest molecular attraction and minimum dipole moment in the solid state, the carboxylate group of one molecule is directed toward the amido group of another molecule in an adjacent layer. The closest distance between different layers (not including hydrogen atoms) thus appears in the vicinity of these groups, and the distances of the $\mathrm{C} 1-\mathrm{O} 1$ and $\mathrm{C} 2-\mathrm{O} 2$ between $\mathrm{A}$ and $\mathrm{B}$ layers are 3.48 and $3.25 \AA$, respectively. For a better understanding of
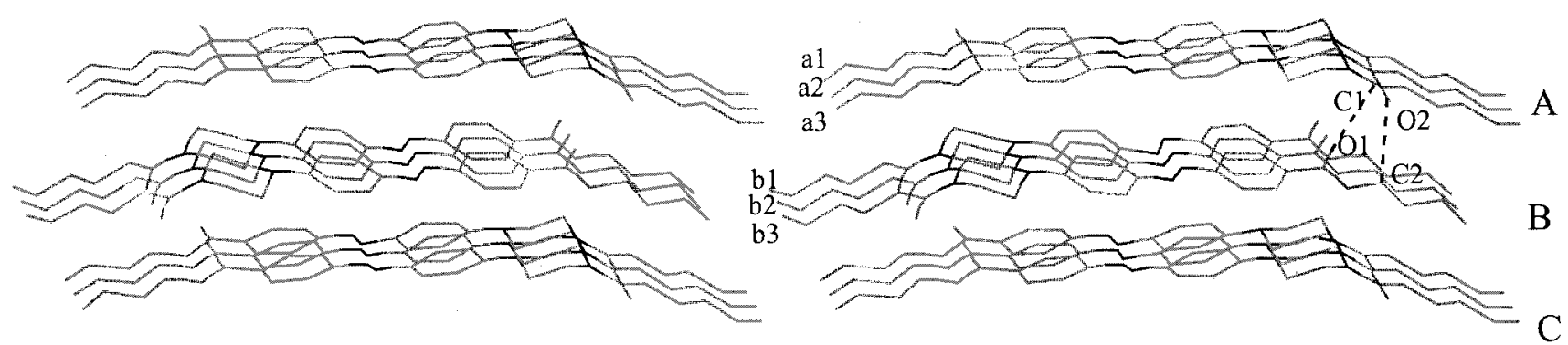

Figure 1. The molecular stacking of azo dye $\mathbf{1}$.

\footnotetext{
*Author for correspondence, e-mail: lilai@ncnu.edu.tw
} 


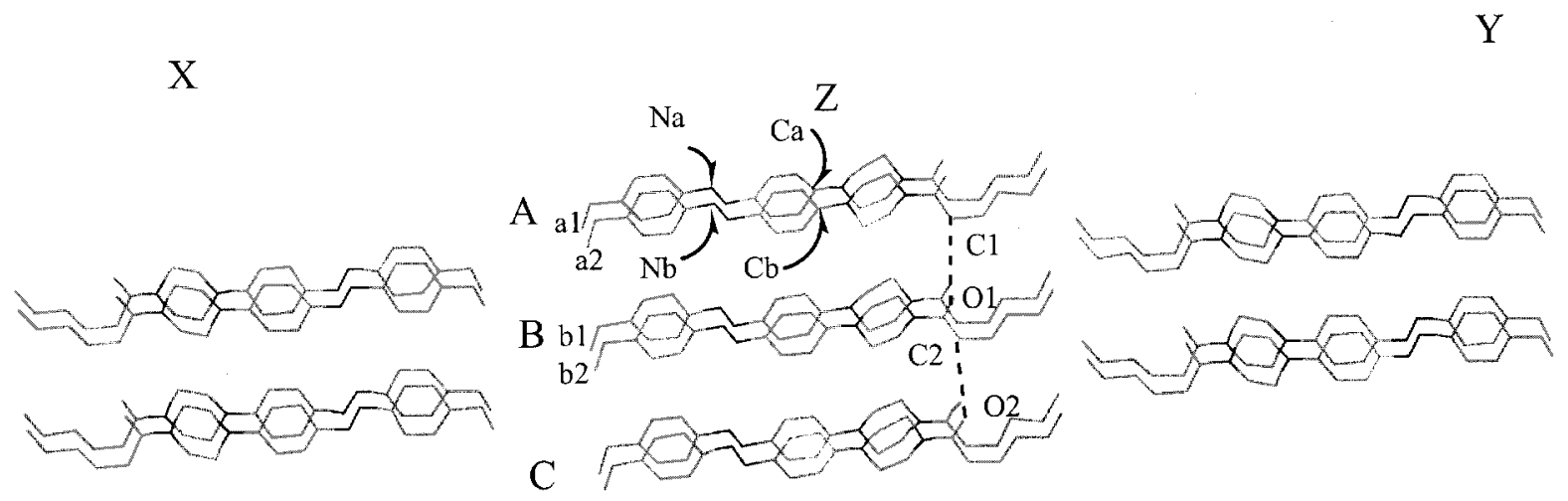

Figure 2. The molecular stacking of azo dye 5a.

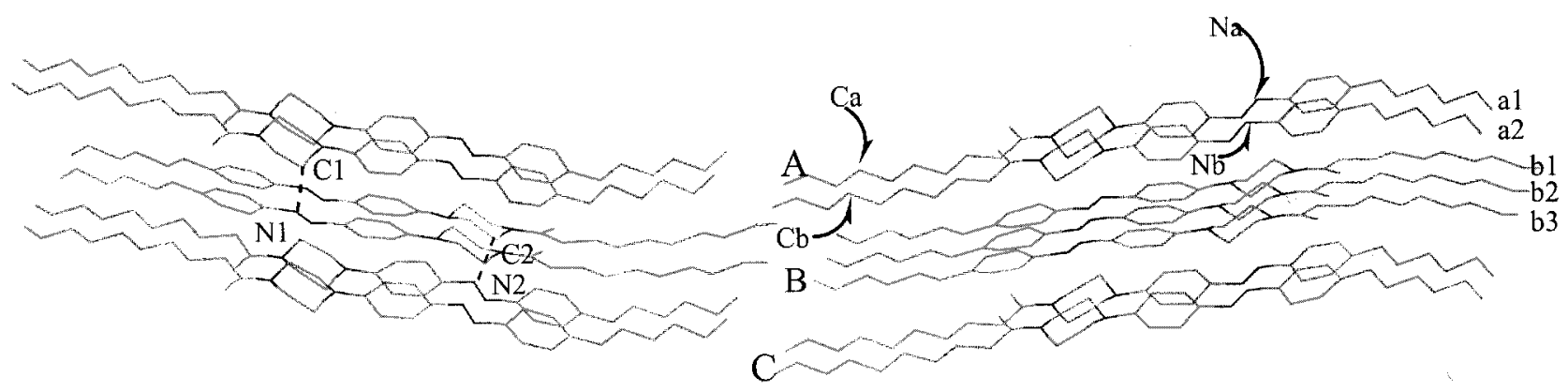

Figure 3. The molecular stacking of azo dye $\mathbf{5 b}$.

the molecular stacking of liquid crystals with different polar moieties, a similar azo dye compound without the carboxylate group has been synthesized and studied by single crystal structure determination. As the driving force for the molecular stacking could be different from the case of azo dye $\mathbf{1}$ which contains amido and carboxylate groups, compounds $\mathbf{5 a}$ and $\mathbf{5 b}$ containing only an amido group were accordingly prepared and their molecular stackings and mesogenic behaviours investigated. We now wish to report preliminary results.

\section{Synthesis}

Compounds $\mathbf{5 a}$ and $\mathbf{5 b}$ were synthesized according to the scheme. Compound $\mathbf{3}$ was first obtained by reaction of $N$-phenylpiperazine with alkanoyl chloride in dichloromethane in an almost quantitative yield. The diazonium salt 4 was then prepared according to the literature method [6]; compounds $\mathbf{5 a}$ and $\mathbf{5 b}$ were subsequently obtained in about $15 \%$ yields, and characterized to be the correct compounds by NMR (Varian 300) and high resolution mass spectroscopy (VG70-250; EI, 70ev).

5a. 17.1\%. ${ }^{1} \mathrm{H}$ NMR: $\delta\left(\mathrm{CDCl}_{3}\right) 0.94\left(\mathrm{t}, 3 \mathrm{H}, \mathrm{CH}_{3}\right)$, $1.33\left(\mathrm{t}, 3 \mathrm{H}, \mathrm{CH}_{3}\right), 1.69-1.78\left(\mathrm{~m}, 6 \mathrm{H}, 3 \times \mathrm{CH}_{2}\right), 2.41$ ( $\left.\mathrm{t}, 2 \mathrm{H}, \mathrm{CH}_{2}\right), 2.75$ (quart, $\left.2 \mathrm{H}, \mathrm{CH}_{2}\right), 3.38(\mathrm{~s}, \mathrm{~b}, 4 \mathrm{H}$, $\left.2 \mathrm{CH}_{2}\right), 3.68\left(\mathrm{t}, 2 \mathrm{H}, \mathrm{CH}_{2}\right), 3.82\left(\mathrm{t}, 2 \mathrm{H}, \mathrm{CH}_{2}\right), 7.01$ $(\mathrm{d}, 2 \mathrm{H}, J=8.7 \mathrm{~Hz}, 2 \times \mathrm{Ar}-\mathrm{H}), 7.34(\mathrm{~d}, 2 \mathrm{H}, J=8.1 \mathrm{~Hz}$, $2 \times \mathrm{Ar}-\mathrm{H}), 7.82(\mathrm{~d}, 2 \mathrm{H}, J=8.7 \mathrm{~Hz}, 2 \times \mathrm{Ar}-\mathrm{H}), 7.91$ $(\mathrm{d}, 2 \mathrm{H}, J=8.1 \mathrm{~Hz}, 2 \times \mathrm{Ar}-\mathrm{H})$. HRMS for $\mathrm{C}_{24} \mathrm{H}_{32} \mathrm{~N}_{4} \mathrm{O}$ :
392.2576; found 392.2578. 5b. $16.5 \% .{ }^{1} \mathrm{H}$ NMR $\delta\left(\mathrm{CDCl}_{3}\right)$ $0.78-0.88\left(\mathrm{~m}, 6 \mathrm{H}, 2 \times \mathrm{CH}_{3}\right), 1.23-1.69\left(\mathrm{~m}, 22 \mathrm{H}, 11 \times \mathrm{CH}_{2}\right)$, $2.35\left(\mathrm{t}, 2 \mathrm{H}, \mathrm{CH}_{2}\right), 2.65\left(\mathrm{t}, 2 \mathrm{H}, \mathrm{CH}_{2}\right), 3.34(\mathrm{~s}, \mathrm{~b}, 4 \mathrm{H}$, $\left.2 \mathrm{CH}_{2}\right), 3.67\left(\mathrm{~s}, \mathrm{~b}, 2 \mathrm{H}, \mathrm{CH}_{2}\right), 3.80\left(\mathrm{~s}, \mathrm{~b}, 2 \mathrm{H}, \mathrm{CH}_{2}\right), 7.01$ $(\mathrm{d}, 2 \mathrm{H}, J=8.7 \mathrm{~Hz}, 2 \times \mathrm{Ar}-\mathrm{H}), 7.27(\mathrm{~d}, 2 \mathrm{H}, J=8.1 \mathrm{~Hz}$, $2 \times \mathrm{Ar}-\mathrm{H}), 7.78(\mathrm{~d}, 2 \mathrm{H}, J=8.7 \mathrm{~Hz}, 2 \times \mathrm{Ar}-\mathrm{H}), 7.92$ $(\mathrm{d}, 2 \mathrm{H}, J=8.1 \mathrm{~Hz}, 2 \times \mathrm{Ar}-\mathrm{H})$. HRMS for $\mathrm{C}_{32} \mathrm{H}_{48} \mathrm{~N}_{4} \mathrm{O}$ : 504.3828; found 504.3830.

\section{Characterization and results}

Compounds $\mathbf{5 a}$ and $\mathbf{5 b}$ were studied by single crystal structure determination $\dagger$, and their corresponding molecular stackings are shown in figures 2 and 3, respectively. In figure 2 , molecules of $\mathbf{5 a}$ in the same column are directed regularly head-to-head and tailto-tail (for example, molecules $\mathrm{a} 1-\mathrm{a} 2$ and $\mathrm{b} 1-\mathrm{b} 2$ in column Z). Furthermore, molecules are found to be

$\dagger$ Crystal data, 5a: $\mathrm{C}_{24} \mathrm{H}_{32} \mathrm{~N}_{4} \mathrm{O}$, crystal dimension $0.45 \times$ $0.25 \times 0.10 \mathrm{~mm}^{3}, P 2_{1}$, monoclinic, $a=7.602(2), b=5.7559(12)$, $c=49.912(10) \AA . ̊, \beta=90.19(3)^{\circ}, Z=4, \rho_{\text {calcd }}=1.194 \mathrm{~g} \mathrm{~cm}^{-3}$, reflections measured $=12334$, reflections used $=3830\left(\left(R_{\text {int }}\right)=\right.$ (0.0390)), $R_{1}=0.0873,[I>2 \sigma(I)], R_{1}=0.1083$ (all data), GOF on $F^{2}=1.158 .5 \mathbf{b}: \mathrm{C}_{32} \mathrm{H}_{48} \mathrm{~N}_{4} \mathrm{O}$, crystal dimension $0.35 \times 0.25 \times$ $0.02 \mathrm{~mm}^{3}, P 2_{1} 2_{1} 2_{1}$, orthorhomic, $a=5.724(2), b=7.364(2)$, $c=67.76(2) \AA, Z=4, \rho_{\text {calcd }}=1.174 \mathrm{~g} \mathrm{~cm}^{-3}$, reflections measured $=$ 8198 , reflections used $=4980\left(\left(R_{\text {int }}\right)=(0.0843)\right), R_{1}=0.0953$, $[I>2 \sigma(I)], R_{1}=0.1760$ (all data), GOF on $F^{2}=1.003$. 


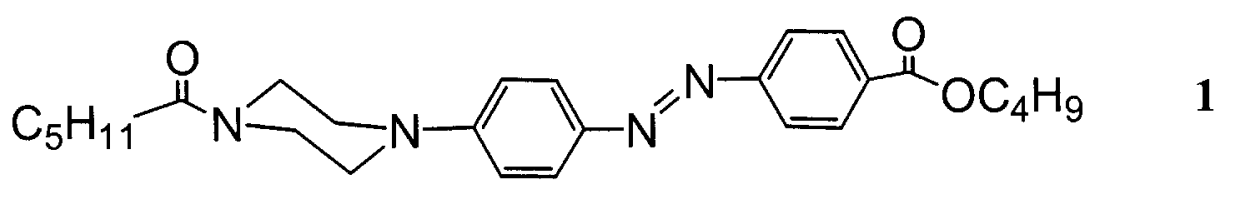

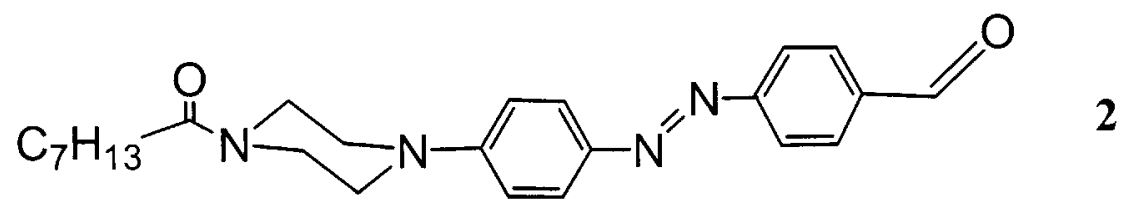<smiles>c1ccc(N2CCNCC2)cc1</smiles><smiles>[R]C(=O)Cl</smiles><smiles>[R]C(=O)N1CCN(c2ccc(N=Nc3ccc([R2])cc3)cc2)CC1</smiles>

5a $\quad \mathrm{R}_{1}=\mathrm{C}_{5} \mathrm{H}_{11}, \mathrm{R}_{2}=\mathrm{C}_{2} \mathrm{H}_{5}$

5b $\mathrm{R}_{1}=\mathrm{C}_{9} \mathrm{H}_{19}, \mathrm{R}_{2}=\mathrm{C}_{6} \mathrm{H}_{13}$

Scheme.

parallel to the adjacent molecules in the same layer (for example, molecules a1-a2 in layer A) and the distances between two corresponding atoms in the same layer (for example, $\mathrm{Na}-\mathrm{Nb}$ and $\mathrm{Ca}-\mathrm{Cb}$ ) are all about 7.6 $\AA$. The plane containing diazobenzene moieties of the molecule in layer A is approximately parallel to the corresponding plane in layer $\mathrm{B}$ and the distance between two parallel planes is about $3.8 \AA$, which is half of the distance between 
Table. Phase transition temperature $\left({ }^{\circ} \mathrm{C}\right)$ and corresponding enthalpies $\left(\mathrm{J} \mathrm{g}^{-1}\right)$, in parentheses, of 5. The phase transition temperatures and corresponding enthalpies of $\mathbf{5}$ were determined by 2 nd DSC scans using a Perkin Elmer DSC-6 at heating and cooling rates of $10^{\circ} \mathrm{C} \mathrm{min}^{-1}$ between 50 and $220^{\circ} \mathrm{C}$. Abbreviations: $\mathrm{Cr}=$ crystalline, SmX $=$ unidentified smectic phase, $\mathrm{SmX}^{\prime}=$ unidentified smectic phase, $\mathrm{SmA}=$ smectic A phase, $\mathrm{I}=$ isotropic liquid.

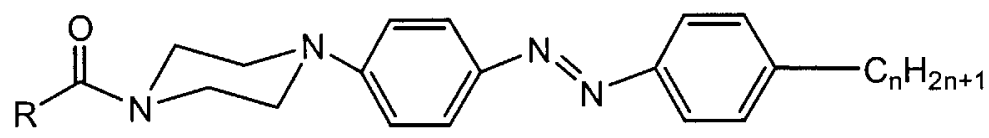

5

\begin{tabular}{|c|c|c|c|c|c|c|c|c|c|c|c|}
\hline $5 \mathrm{a}$ & $\begin{array}{l}n=2 \\
R=\mathrm{C}_{5} \mathrm{H}_{11}\end{array}$ & $\mathrm{Cr} 1$ & $\rightleftharpoons_{56.6}^{125.7(40.1)} \stackrel{\rightleftharpoons}{=}$ & $\operatorname{SmX}$ & $\sum_{63.0 \mathrm{~b}}^{138.6}$ & $\geq$ & $\operatorname{Sm} X^{\prime}$ & $\bar{F}_{137.6(3.6)}^{141.1^{\mathrm{a}}} \rightleftharpoons$ & $\mathrm{SmA}$ & $\stackrel{187.4(11.6)}{\rightleftharpoons}_{F_{0.0(12.8)}}^{\stackrel{\bar{\rightleftharpoons}}{ح}}$ & I \\
\hline $5 \mathrm{~b}$ & $\begin{array}{l}n=6 \\
R=\mathrm{C}_{9} \mathrm{H}_{19}\end{array}$ & $\mathrm{Cr} 1$ & $\bar{F}^{104.1(16 .} \begin{array}{c}56.6 \\
5\end{array}$ & 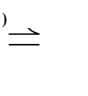 & $\operatorname{SmX}$ & $\mp$ & $={ }_{153.1(5.4)}^{154.1(6.8)}=$ & $\mathrm{SmA}$ & $\mp$ & $\begin{array}{l}195.1 \overline{(15.5)} \\
192.7(14.5)\end{array}$ & I \\
\hline
\end{tabular}

a The peaks are overlapped and their total enthalpy is $4.5 \mathrm{~J} \mathrm{~g}^{-1}$.

${ }^{\mathrm{b}}$ The peaks are overlapped and their total enthalpy is $26.5 \mathrm{~J} \mathrm{~g}^{-1}$.

corresponding atoms in the same layer. The closest distance between two adjacent layers (not including hydrogens) is $3.88 \AA$, found, for example, at the $\mathrm{C} 1-\mathrm{O} 1$ between layers $\mathrm{A}$ and $\mathrm{B}$ as well as at $\mathrm{C} 2-\mathrm{O} 2$ between layers $\mathrm{B}$ and $\mathrm{C}$. The distances $\mathrm{O} 1-\mathrm{H}($ at $\mathrm{C} 1$ ) and $\mathrm{O} 2-\mathrm{H}$ (at C2) are both $3.01 \AA$, which are in the range of a normal hydrogen bond $[7 a]$. After careful examination of molecular stacking, we do not find that the interatomic distance in different molecules is closer than this value. We thus believe that the driving force for the stabilization of molecular stacking of azo dye $\mathbf{5 a}$ mostly arises from intermolecular hydrogen bonding.

In figure 3, molecules of $\mathbf{5 b}$ are directed regularly headto-head and tail-to-tail in the same layers (for example, molecule a1-a2 in layer A). However, molecules in adjacent layers are arranged head-to-tail (for example, molecules $\mathrm{a} 1-\mathrm{a} 2$ in layer $\mathrm{A}$ and molecules $\mathrm{b} 1-\mathrm{b} 3$ in layer B). In the same layer, the molecules are found to be parallel to adjacent molecules and the distances between two corresponding atoms in the same layer (for example, $\mathrm{Na}-\mathrm{Nb}$ and $\mathrm{Ca}-\mathrm{Cb}$ ) are all about $5.72 \AA$. Molecules in different layers are not parallel to each other. The intercept angle between the plane containing diazobenzene moieties of the molecules in layer $\mathrm{A}$ and the corresponding plane in layer B is estimated at about $40^{\circ}$ on the basis of crystallographic data. The closest distance between two adjacent layers (not including hydrogens) is $3.37 \AA$, which is, for example, found at the $\mathrm{C} 1-\mathrm{N} 1$ between $\mathrm{A}$ and $\mathrm{B}$ layers, as well as $\mathrm{C} 2-\mathrm{N} 2$ between $\mathrm{B}$ and $\mathrm{C}$ layers. The distances of $\mathrm{N} 1-\mathrm{H}$ (at $\mathrm{C} 1$ ) and $\mathrm{N} 2-\mathrm{H}$ (at $\mathrm{C} 2$ ) are both $2.82 \AA$ which is comparable to the sum of the van der Waals radii of $\mathrm{H}$ and $\mathrm{N}$ (Bondi radius: $\mathrm{H}$ 1.20, $\mathrm{N}$ 1.55) [7 b]. The $\mathrm{H}$-bond interaction arising therefrom should be influential in the crystallizing process and is believed to be the major contribution to stabilization of the molecular stacking of compound $\mathbf{5 b}$.

Based on the previous results, we may reasonably regard that for a bi-polar compound such as azo dye $\mathbf{1}$, the polarity of functional groups determines the orientation of the molecular arrangement in the crystal structure. However, for mono-polar compounds such as azo dyes $\mathbf{5 a}$ and $\mathbf{5 b}$, the intermolecular hydrogen bonding interaction is most influential for the molecular stacking. Additionally, it is interesting to note that molecule 5a is in a linear arrangement, but there is a slight bending between the piperazine and decanoyl moieties in structure $\mathbf{5 b}$. The hexyl tail at the other end of molecule $\mathbf{5 b}$ makes this bending more pronounce $d$ and thus the whole molecule is arranged in a slightly curved shape. Compounds 5a and $\mathbf{5 b}$ both show a SmA phase in thermal cycling, characterized by a focal-conic texture under polarizing optical microscopy (see the table), which is different from the mesogenic behaviour of azo dye $\mathbf{1}$ which shows a SmC phase $[5 a]$.

Based on the crystallographic study, the extended molecular lengths of azo dyes $\mathbf{5 a}$ and $\mathbf{5 b}$ are calculated to be 24.08 and $32.83 \AA$, respectively, which are quite close to the corresponding $d$-spacing distances of azo dyes $\mathbf{5} \mathbf{a}$ and $\mathbf{5 b}$ in the SmA phase, obtained from powder $\mathrm{X}$-ray diffraction (XRD) . Although the amido moiety

The $d$-spacings of compound 5a are 24.95, 25.09, 25.09, $25.11,25.24 \AA$ at $180,170,160,150,140^{\circ} \mathrm{C}$, respectively, during cooling; the $d$-spacings of compound $\mathbf{5 b}$ are $32.88,32.86,32.70$, $2.45,32.41 \mathrm{~A}$ at $188,185,175,165,155^{\circ} \mathrm{C}$, respectively, during cooling. Powder XRD patterns were obtained from a Siemens D-5000 X-ray Diffractometer equipped with a TTK 450 temperature controller. 
of compounds $\mathbf{5 a}$ and $\mathbf{5 b}$ may vibrate up and down during the thermal process, the extended length of the molecules may not change much as a result. According to the literatures, the $N$-substituent of the piperazine favours equatorial conformation, and the energy barrier between the equatorial and axial conformations is only about $1.9-4 \mathrm{kcal} \mathrm{mol}^{-1}$ [8]. As we have shown in the case of azo dye $1[5 a]$, the $N$-substituent in either equatorial or axial conformation does not significantly change the extended molecular length. Thus the $d$-spacing of the molecules will not vary much during thermal processing; this is consistent with the observations obtained from powder XRD.

\section{Conclusion}

While exploring crystal stacking with varying molecular polarity, compounds $\mathbf{5 a}$ and $\mathbf{5 b}$ were investigated by crystallography and the study of mesogenic behaviour. As mentioned previously, for the bi-polar azo dye 1, the mutual attraction from amido and carboxylate groups of different molecules affects the molecular stacking in the crystal structure. For the mono-polar azo dyes 5a and $\mathbf{5 b}$, intermolecular hydrogen bonding is the major contribution to stabilization of the molecular stacking. These results provide not only a better understanding of the effect of the functional group and hydrogen bonding on the stacking of liquid crystals in the solid state, but also provide a useful guide for the future design of desired materials.
We thank the National Chi Nan University and the National Science Council (NSC 90-2113-M-260-002) for financial support. The National Center of HighPerforming Computing and the Institute of Chemistry, Academia Sinica are also highly appreciated for providing the Beilstein database system, as well as a most helpful library service and the XRD apparatus, respectively.

\section{References}

[1] (a) LeHN, J.-M., 1995, Supramolecular Chemistry (Weinheim: VCH); (b) Hamilton, A. D., 1996, Perspectives in Supramolecular Chemistry (John Wiley).

[2] (a) Hunter, C. A., 1993, Angew. Chem. int. Ed. Engl., 32, 1584; (b) Hunter, C. A., 1994, Chem. Soc. Rev., $23,101$.

[3] (a) Desiraju, G. R., 1989, Crystal Engineering: The Design of Organic Solids (New York: Elsevier); (b) DesiraJu, G. R., 1997, Chem. Commun., 1475.

[4] (a) Lee, K. M., Lee, C. K., and Lin, I. J. B., 1997, Angew. Chem. int. Ed. Engl., 36, 1850; (b) Chang, J., and Moore, J. S., 1994, J. Am. chem. Soc., 116, 2655.

[5] (a) Lai. L. L., Lee, L. J., Lee, G. H., WANG, Y., LU, K. L., and LeE, S. J., 2001, Liq. Cryst., 28, 1513; (b) LaI, L. L., Lin, Y. J., Ho, C. H., WANG, E., LiU, Y. H., Wang, Y., Lin, Y. C., and Cheng, K. L., 2001, Helv. Chim. Acta (in the press).

[6] McNab, H., and Monahan, L. C., 1989, J. chem. Soc. Perkin Trans. 1, 419.

[7] Allen, F. H., Lommerse, J. M. P., Hoy, V. J., Howard, J. A. K., and Desiraju, G. R., 1996, Acta Cryst., B52, 734; (b) Bondi, A., 1964, J. phys. Chem., 68, 441.

[8] (a) Baker, V. J., Ferguson, I. J., Katritzky, A. R., and PATEL, R., 1976, Tetrahedron. Lett., 4735; (b) NIEMEYER, H. M., 1979, J. mol. Struct., 57, 241. 
Copyright of Liquid Crystals is the property of Taylor \& Francis Ltd and its content may not be copied or emailed to multiple sites or posted to a listserv without the copyright holder's express written permission. However, users may print, download, or email articles for individual use. 